\title{
Ballistic performance of the steel-aluminium metal laminate panel for armoured vehicle
}

\author{
S. Abdullah ${ }^{*}$, M.F. Abdullah², W.N.M Jamil ${ }^{1}$ \\ ${ }^{1}$ Centre for Materials Engineering and Smart Manufacturing, Faculty of Engineering \& Built Environment, Universiti Kebangsaan Malaysia, \\ 43600 UKM Bangi, Selangor, Malaysia. \\ ${ }^{2}$ Department of Mechanical Engineering, Faculty of Engineering, Universiti Pertahanan Nasional Malaysia, Kem Sg. Besi \\ 57000 Kuala Lumpur, Malaysia.
}

\begin{abstract}
This paper presents the ballistic performance of the joining lightweight metal laminated panel consists of high strength steel and aluminium alloy for armoured vehicle application. Composite laminates trend in military industry present excellent performance in terms of lightweight material due to the improvement vehicle manoeuvrability, without sacrificing the performance and safety. The combination of aluminium plate and high strength steel offer the good potential for reducing the vehicle weight and improving the ballistic resistance. Ar500 and Al7075-T6 were chosen in designing laminated panel to achieve intended $20-30 \%$ weight reduction. Joining between these two materials have been investigated using both brazing method and adhesive bonding method. The adhesive bonding involved two types of material which is epoxy and polyurethane. Mechanical tests such as bending tests, drop weight tests and ballistic tests were performed to assess the strength of the laminated panel. Results showed that polyurethane bonded laminate panel through adhesion process exhibited $75 \%$ higher strength that that through the brazing process after performing impact test. Meanwhile, the penetration patterns found numerically are nearly similar to that from the ballistic tests and thus has validated the finite element models developed. The study on application of this laminated plate shall be extended using higher level of threat for hard armour vehicle panel.
\end{abstract}

ARTICLE HISTORY

Revised: $18^{\text {th }}$ Oct 2019

Accepted: $20^{\text {th }}$ Nov 2019

\section{KEYWORDS}

lightweight;

metal-laminate;

brazing joining;

adhesive bonding;

ballistic impact.

\section{INTRODUCTION}

Steel has been used in armour applications due to their good performances of high strength and hardness [1]. Nevertheless, steel is very heavy which has limited the vehicle mobility. The development of composite materials reduces the weight while retaining the strength [2]. The recent development in armour vehicle industry is to combine the lightweight materials such as ceramic, magnesium alloys, aluminium alloys and titanium alloys for weight reduction [3]. Aluminium alloys have becomes an interest in weight reduction of armoured vehicle body because of their performance in terms of high ductility, high stiffness-to-weight ratio and good corrosion resistance [4]. The combination of the steel and aluminium will maintain the original strength as the weight will be reduced. Aluminium alloys has a higher ductility to absorb the remaining energy of the projectile causes by front plate. Hence, Aluminium alloys offer the weight reduction in combination with the others materials [2]. Forrestal et al. [5] found that the integration of the Al7075-T6 and Al5083H116 with steel increase the ballistic performance for armoured vehicle structures. Hence, the combination of the aluminium alloy and steel will improve the ballistic performance while reducing the weight of the panel.

The main criterion for an armoured vehicle performance is its ballistic impact resistant capability resulting from high velocity impact by a low mass projectile. The materials used in the laminated panel must also not compromise the stiffness and strength of the vehicle panel in both low velocity and high velocity impact because structural resistance to severe impacts is directly related to structural integrity [6]. Structural performance in low velocity must also be considered because force transmissions between layers in laminated panels are related closely with the deformation and energy absorption capability of the panels [7, 8]. Thus, it is essential to better understand the local strength and energy-absorbing characteristics of layered panel with joining materials in order to determine the behaviour and properties of new panel to be used in these vehicles in terms of its strength during low velocity impact while considering the high velocity impact such as ballistic impact. The joining process of welding, riveting, brazing, and adhesive bonding was used to join the plates. Adhesive and brazing joining process offer some advantages from other process such as homogeneous stress distribution on a surface of the material, wide stress-bearing region, superior damping and shock-absorbing properties.

The adhesive may lead to deform causes by plastic zone at the end of the adhesive bonding initiates. The white band will be produced because of the damage zone [9]. The theoretical work of adhesion was compared by an experiment to measure the strength of the joint $[10,11]$. Consequently, the plastic dissipation of adhesive layer produced from the remaining strength of the bonding reflects the findings of by Gent et al. [12]. Although the joining process like adhesion 
technique and brazing technique have been broadly used, there are still concern in fabricate reliable strength under low velocity impact

Hence, it is important to understand the properties and strength of the joining in order to produce the strong joint for metal laminates panel. Introducing the joining material into the metal laminate panel would improve its ballistic impact resistance. In order to enhance the attractiveness of laminated plate construction inclusive the joining material through adhesion technique and brazing technique, it is essential to study the strength of the joint dissimilar metals under low velocity impact before performing the ballistic impact. Therefore, this paper will be focused to study the effect of dissimilar joining methods for aluminium alloy and high strength steel subjected to low velocity and ballistic impact using both experiment and numerical methods. The metal laminate panel was joined using adhesion and brazing technique and was subjected to low velocity impact tests and high velocity impact test. The impact performance in terms of maximum stresses, forces, deflections and penetration depth was evaluated to determine the most suitable joining material and process for this laminated panel.

\section{METHODOLOGY}

The methodology frameworks employed in this study are illustrated in Figure 1. Combining dissimilar metals of Ar500 steel and Al7075-T6 aluminium will contributed in weight reduction and increased ballistic performance due to their high strength and hardness. Tensile test and hardness test were carried out to study the properties of the materials. Then, joining process was performed using two types of joining technique: brazing technique and adhesive technique. Low velocity impact test was conducted on the joined dissimilar metals using bending test and drop test to evaluate low velocity impact on the laminated panel. Finally, ballistic test was conducted using simulation works and experiment. The experiment was conducted for laminated panel without joined materials for validation of finite element model only. The effect of laminated panel with joined materials under ballistic impact was investigated through finite element analysis. The experimental approach can provide good penetration results, but it is very expensive. The finite element approach on the other hand has been proven to be a reliable and economical tool for penetration predictions of projectiles over all ranges of striking velocities [13].

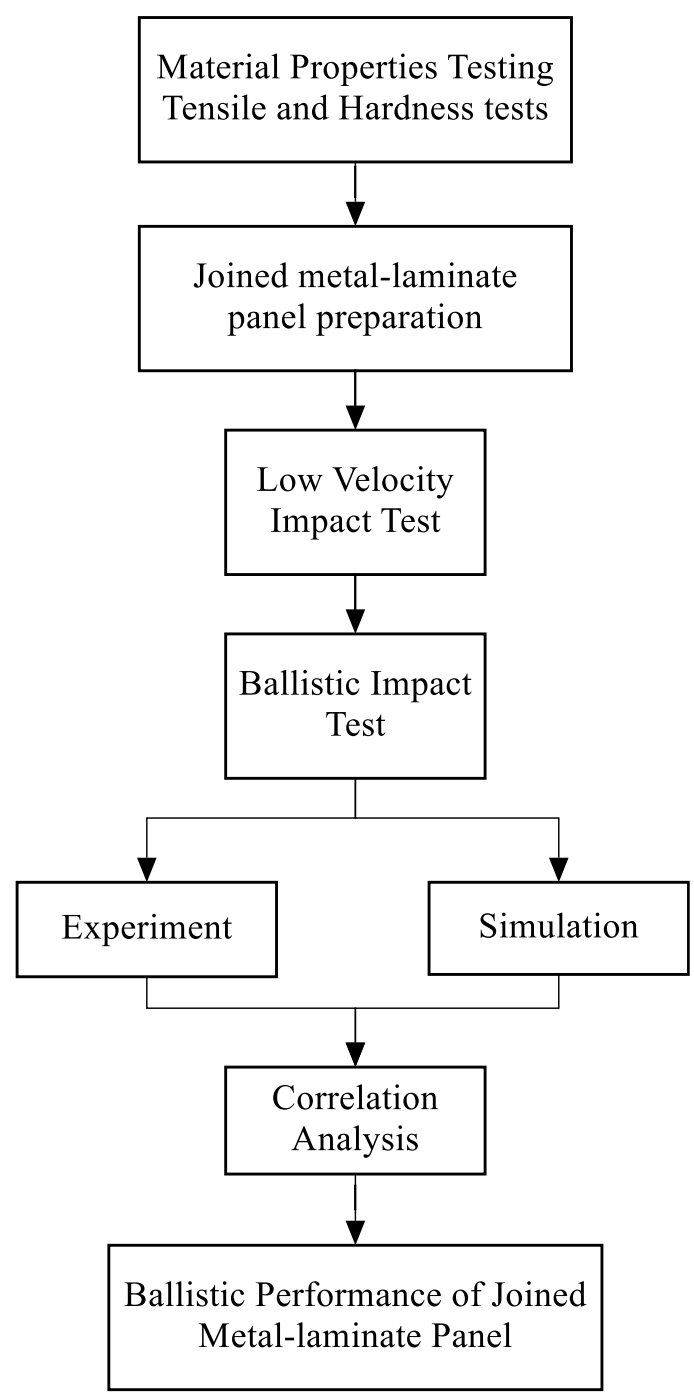

Figure 1. Flow diagram of the methodology. 


\section{Experimental Procedure}

Figure 2 presents the dog-bone shaped specimen for tensile test which was prepared based on the ASTM E8. The cross section and the length of the gauge area were $6 \mathrm{~mm} \times 6 \mathrm{~mm}$ and $25 \mathrm{~mm}$, respectively. Tensile test was performed on Ar500 steel, Al7075-T6 aluminium, Epoxy adhesive, Polyurethane adhesive and Al-Si-Zn filler metal using the universal testing machine of $100 \mathrm{kN}$ capacity and the specimens were strained at a speed of $1.5 \mathrm{~mm} / \mathrm{min}$ to obtain the stress-strain curve for mechanical properties analysis. Meanwhile, the diameter of steel ball indenter's is $12.7 \mathrm{~mm}$ and test force is $588.4 \mathrm{~N}$ was set in $\mathrm{R}$ scale for the Rockwell hardness test in all joining process. The diameter of the steel ball was $1.6 \mathrm{~mm}$ at $980.7 \mathrm{~N}$ for Ar500 steel, Al7075-T6 aluminium and Al-Si-Zn filler metal by using B scale. All specimens were placed on a pressing platform, and the hardness was obtained once they reached their respective force. The Rockwell hardness B tester was used to measure the hardness of metallic materials while Rockwell hardness R tester was used to measure the hardness of plastics and insulating materials according to ASTM D785 standard test method. The mechanical properties of the steel, aluminium alloy and joining materials are presented in Table 1.

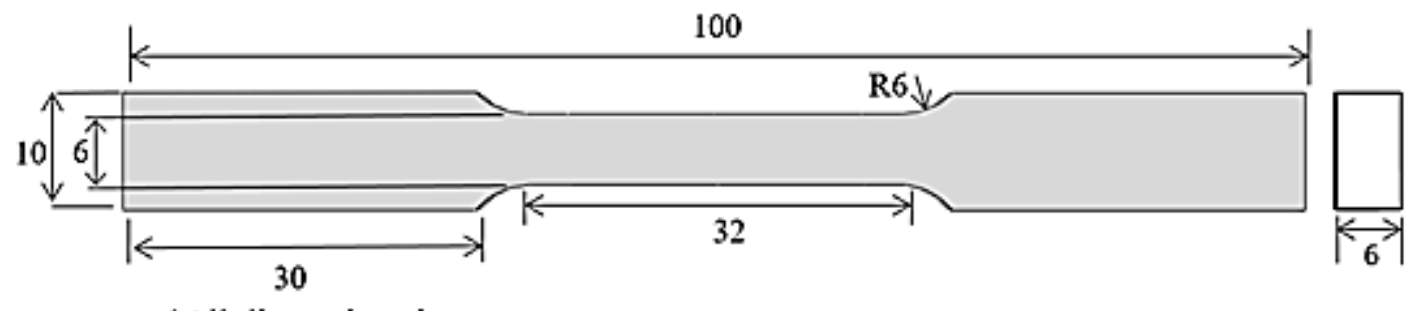

*All dimensions in mm

Figure 2. Geometrical properties of the specimen used for tensile test.

Table 1. Mechanical properties of materials used for laminated panel.

\begin{tabular}{cccccc}
\hline Material & $\begin{array}{c}\text { Density } \\
\left(\mathrm{kg} / \mathrm{m}^{3}\right)\end{array}$ & Hardness & $\begin{array}{c}\text { Tensile strength } \\
(\mathrm{MPa})\end{array}$ & $\begin{array}{c}\text { Yield stress } \\
(\mathrm{MPa})\end{array}$ & $\begin{array}{c}\text { Elongation at } \\
\text { break }(\%)\end{array}$ \\
\hline Ar500 & 7850 & $115 \mathrm{HRB}$ & 1740 & 1370 & 12.5 \\
Al7075-T6 & 2804 & $84 \mathrm{HRB}$ & 536 & 480 & 10.0 \\
Epoxy & 1200 & $110 \mathrm{HRR}$ & 48.7 & 31.1 & 2.1 \\
Polyurethane & 1150 & $84 \mathrm{HRR}$ & 19.6 & 16.7 & 2.1 \\
Filler metal & 2600 & $31 \mathrm{HRB}$ & 144 & 69 & 5.8 \\
\hline
\end{tabular}

The Al7075-T6 aluminium and Ar500 steel were joined using two techniques: brazing technique and adhesive technique. Brazing technique was performed using torch brazing process and the filler metal Al-Si-Zn as the joining materials. Torch brazing process was conducted with flame produced by butane gas and heated on the surface of steel until the metal filler is melt as shown in Figure 3. Meanwhile through adhesive technique, Al7075-T6 and Ar500 were joined using two types of joining materials: epoxy and polyurethane. Adhesive joining process was performed by which metal was held together by the surface attachment of adhesives. Adhesive process occurs when the liquids or paste is converted into a solid state. The change was achieved through polymerization and heat curing. These three specimens of joined dissimilar metals were tested under low velocity impact: shear lap joint test, drop test and bending test. A shear lap joint is set in ASTM D1002 for standardised condition. A universal tensile testing machine was utilised to obtain the shear strength of the joint. As described above, specimens were gripped with excessive force to avoid slippage, and the cross head speed was set at $1.3 \mathrm{~mm} / \mathrm{min}$. To minimise bending stress inherent in the testing of joined specimens, the gripping section of the specimen was fabricated thicker to obtain an axis parallel to that of the loading point.

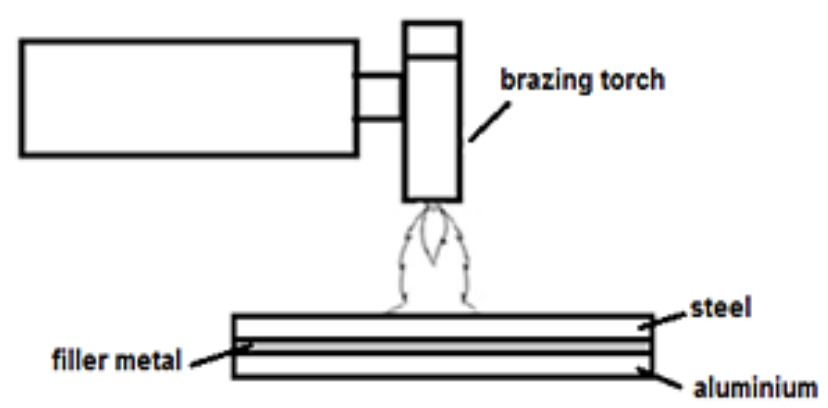

Figure 3. Schematic illustration of torch brazing process 
A three-point bending test was also carried out using a universal testing machine according to ISO 14125, at a cross head speed of $5 \mathrm{~mm} / \mathrm{min}$ at room temperature. This cross head speed was chosen to achieve the minimum stress rate to match the semi-static loading requirement. The flexural strength of the specimen was calculated by measuring the fracture force from the stress-strain curve as in Equation. (1):

$$
\sigma_{f}=\frac{3 F L}{2 b d^{2}}
$$

where $\sigma_{f}$ is the flexural strength $(\mathrm{MPa}), L$ represent the distance between the support points (mm), $F$ is defined as the load at fracture $(\mathrm{N})$, while $b$ and $d$ represent the cross-sectional width $(\mathrm{mm})$ and height $(\mathrm{mm})$, respectively of the specimen. Drop test was performed by using drop impact testing machine. Two plates in spherical opening were griped the laminated panels in the impact fixture of diameter $70 \mathrm{~mm}$. The hemispherical striker with a diameter of $20 \mathrm{~mm}$ was used to perform impact tests. The indenter mass was $13 \mathrm{~kg}$ whereas the impact energy was $20 \mathrm{~J}$. Different process of adhesive and brazing were used to evaluated the peak force and impact damage.

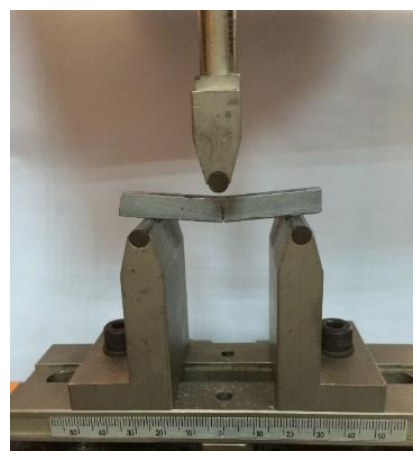

(a)

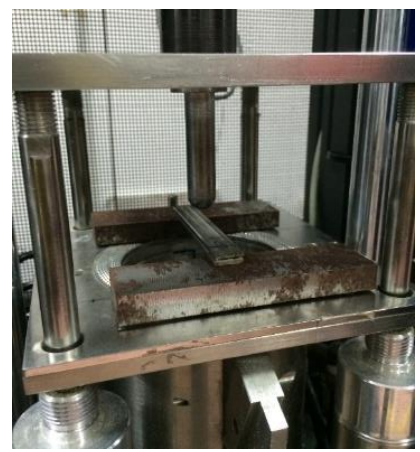

(b)

Figure 4. (a) A three point bending position on a universal testing machine, (b) A set-up for a drop test machine.

In addition, the ballistic test was carried out to validate the finite element model of the laminated panel without joining materials. The triple-layered panel consists of front layer with 8 -mm thick steel, intermediate layer with 10 -mm thick aluminium alloy and back layer with 7-mm thick as shown in Figure 5. The laminated panel achieving the 25\% weight reduction from existing ballistic resistant panel. The ballistic tests were performed using NATO Stanag 4569 standard which specifies the protection levels for armoured vehicles in five categories [14]. The threat by this study is level 2 which is one level lower than the practice standard for an armoured vehicle should surpass to protect occupants. The experimental result was then compared with the finite element result and the study was then extended to the higher level of threat which is NATO Stanag 4569 protection level 3.

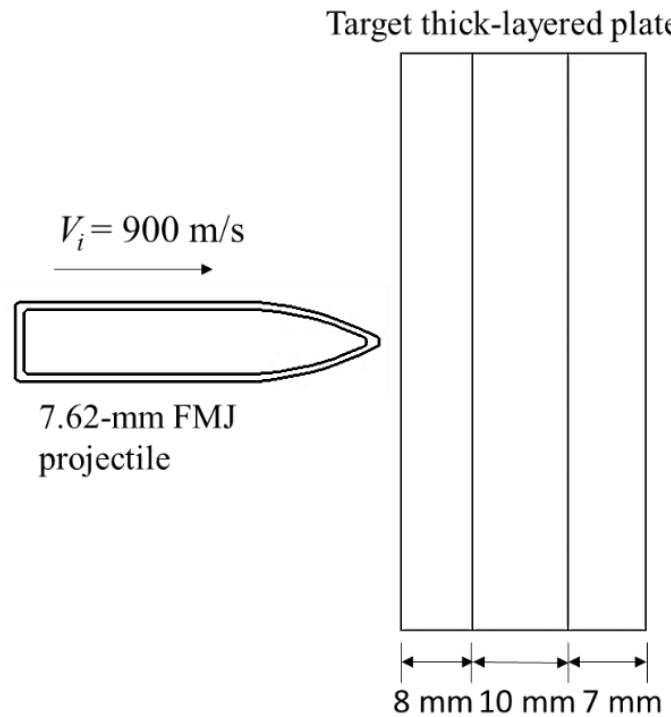

Figure 5. The cross-section geometrical model of the 7.62-mm FMJ projectile and thick-layered armour test plates for metal laminates panel. 


\section{Numerical Procedure}

The geometrical model of $7.62 \mathrm{~mm}$ armour piercing ammunition projectile and the triple-layered target panel as in Figure 5 was modelled using a Ansys AutoDYN software package suitable for high velocity impact. The total mass of projectile is $10.04 \mathrm{~g}$ with $7.7 \mathrm{~mm}$ diameter and $35 \mathrm{~mm}$ length, and it is made of a brass jacket, lead filler and ogive nose hardened steel core. The target plate was modelled as $100 \mathrm{~mm}$ diameter circular plate and fully clamped at the edge boundaries. Four models of triple-layered configuration panels were constructed where Al7075-T6 was placed in the intermediate layer and Ar500 was placed in the front and back layers. One model was developed without joining material as the reference panel. Other three models were constructed by which each layer was joined using three types of joining materials: filler metal Al-Si-Zn, epoxy and polyurethane.

The Johnson Cook (JC) material constitutive model was used to represent the projectile and metal-laminate panel of Ar500 steel and Al7075-T6 aluminium while the Cowper-Symonds (CS) material constitutive model was utilised to represent the joining materials in finite element model. The JC parameters for Ar500 steel, Al7075-T6 and projectile materials used in this study shown in Table 2 are adopted from the previous works of Forrestal et al. (2010) and Manes et al. (2014). These JC parameters were chosen because the materials used in the previous works have almost comparable material properties of density, Young's modulus and Poisson's ratio with that from this study. However, CS was chosen over JC model to represent the joining materials because of its simplicity. It was quite difficult to find the JC parameters for the joining materials and it seems unnecessary to use JC model because the balance strength of joints was contributed by plastic joining material layer and CS model is based on conventional plasticity theory solely and the effect of joining material over a ballistic impact is not as much as the Ar500 steel and Al7075-T6 aluminium [15]. CS parameters for joining materials were calculated from experimental procedure conducted using the static and semi-static loading tests and were tabulated in Table 2.

Table2. Cowper-Symonds parameters for joining materials.

\begin{tabular}{cccc}
\hline Cowper-Symonds Constant & Al-Si-Zn filler metal & Epoxy & Polyurethane \\
\hline$C$ & 120 & 2188 & 50 \\
$q$ & 5.0 & 5.5 & 4.0 \\
\hline
\end{tabular}

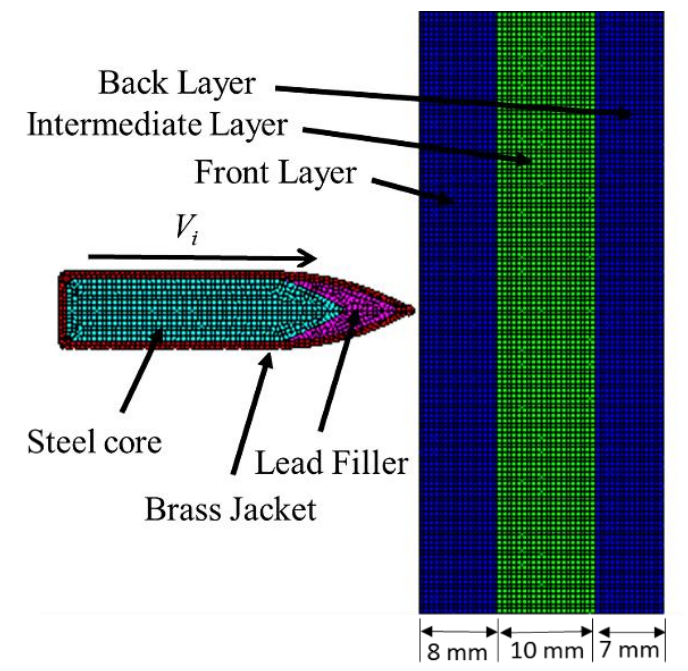

(a)

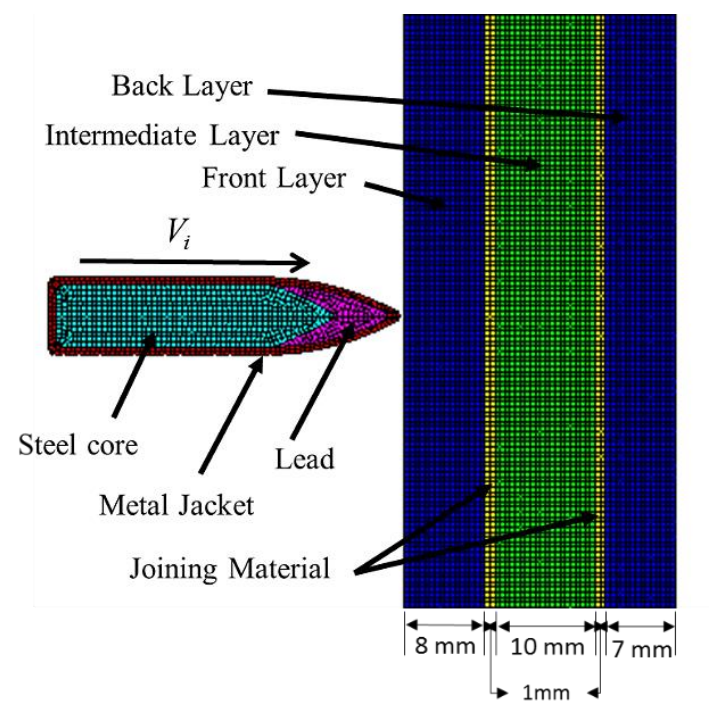

(b)

Figure 6. Finite element model of projectile and laminated plate for:

(a) Laminated panel without joining material, (b) Laminated panel with joining materials.

\section{RESULTS AND DISCUSSION}

Joining process was performed to join Ar500 and Al7075 plates as a laminated panel using three different joining materials: Al-Zn-Si filler through brazing process and epoxy and polyurethane through adhesion process. Three low velocity impact tests were conducted and the results were summarised in Table 3 . The shear strength values of both specimens are presented in Figure 7. Results indicate that epoxy joined laminated panel exhibits highest shear strength of 15.8 MPa which is $35 \%$ and $75 \%$ higher than that of the polyurethane and Al-Zn-Si filler joined laminated panel. Epoxy specimen has higher strength compared to polyurethane due to better stress distribution under semi-static load of bending test. However, the strength performance of adhesive-bonded metal laminates under drop test at high strain rate was 
different from the semi-static load. Failure occurs at interfacial bond of Al7075-Epoxy due to bending effect of Al7075. Epoxy specimen has higher deflection compared to polyurethane in semi static load as in Figure 8. However, under higher velocity or higher strain rate, the study indicates that polyurethane joined laminated panel exhibits a higher performance compared to epoxy and Al-Zn-Si joined metal laminates specimen. Polyurethane cracked at the highest load of $2979 \mathrm{~N}$ and polyurethane joined panel can withstand a higher load before cracks begin to initiate in the metal laminates.

The strength performance of adhesive-bonded metal laminates was higher at high strain rates (drop test) contrast to the low strain rates (bending test). Elastic properties of the polymeric material in which when a load is applied molecular chains will experience a phase of restructuring before plastic deformation because the adhesive bonding increases in stiffness at higher strain rate [16]. Under partial load static pressure, constituent molecular chains occur relaxed and effectively facilitate it undergoes plastic deformation phase. However, under the influence of the impact load at high strain rates, the molecular chain is not able to sort position, then it will intersect with each other and confined its deformation slip [17]. It appears from the Figure 9 where the maximum load and elongation of epoxy adhesive is higher, showing the ability to absorb lower energy. While the percentage of cracks in both samples when subjected to energy of $20 \mathrm{~J}$ is $100 \%$ of the epoxy-bonded panel and $50 \%$ for polyurethane-bonded panels. Epoxy-bonded and Al-Zn-Si filler bonded panels were detached, while polyurethane-bonded panel remained attached to the substrate as shown in Figure 10 .

Table 2. Summary results of low velocity impact tests on metal laminated panel with joining material.

\begin{tabular}{cccccc}
\hline \multirow{2}{*}{ Joining Material } & Shear test & \multicolumn{2}{c}{ Bending Test } & \multicolumn{2}{c}{ Drop Test } \\
\cline { 2 - 6 } & $\begin{array}{c}\text { Maximum } \\
\text { Stress (MPa) }\end{array}$ & $\begin{array}{c}\text { Maximum } \\
\text { Force }(\mathrm{N})\end{array}$ & $\begin{array}{c}\text { Deflection } \\
(\mathrm{mm})\end{array}$ & $\begin{array}{c}\text { Maximum } \\
\text { Force }(\mathrm{N})\end{array}$ & $\begin{array}{c}\text { Deflection } \\
(\mathrm{mm})\end{array}$ \\
\hline Epoxy & 15.8 & 3480 & 7.9 & 2017 & 19.1 \\
Polyurethane & 10.2 & 1322 & 15.6 & 2979 & 17.5 \\
Al-Zn-Si Filler & 4.1 & 615 & 11.5 & 1690 & 26.8 \\
\hline
\end{tabular}

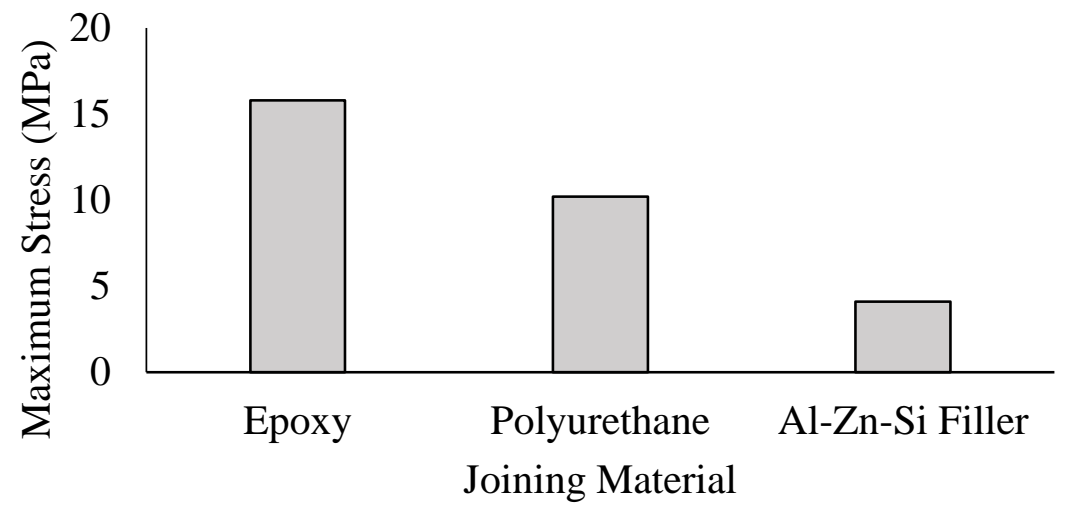

Figure 7. Maximum strength of different joining materials subjected to shear test.

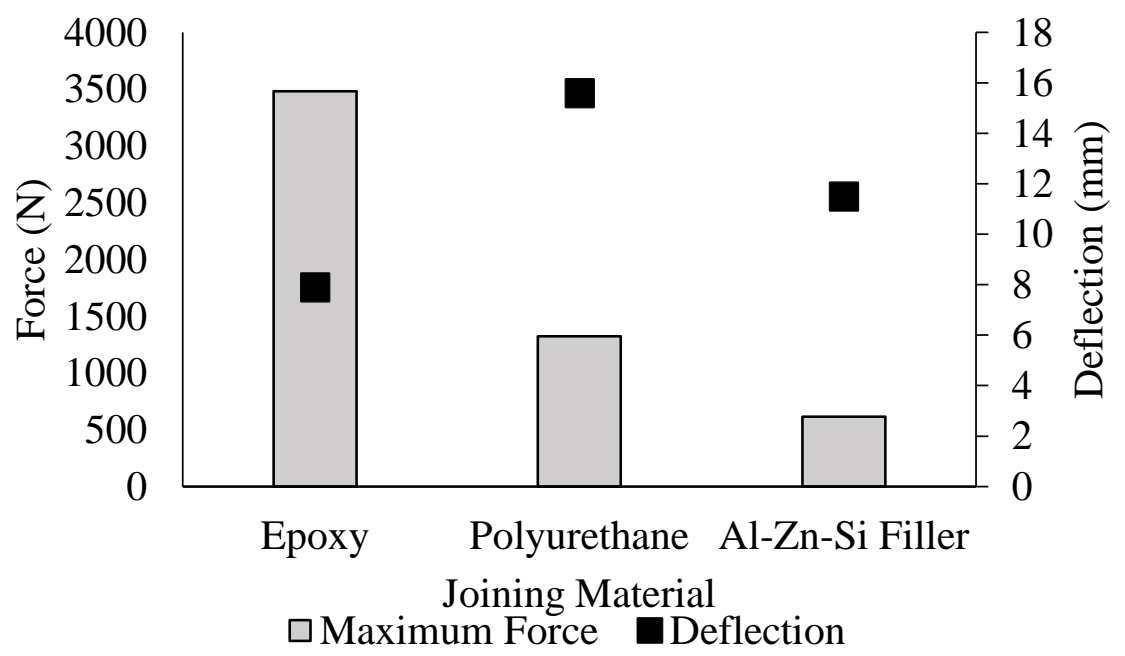

Figure 8. Force and Deflection of different joining materials subjected to bending test. 


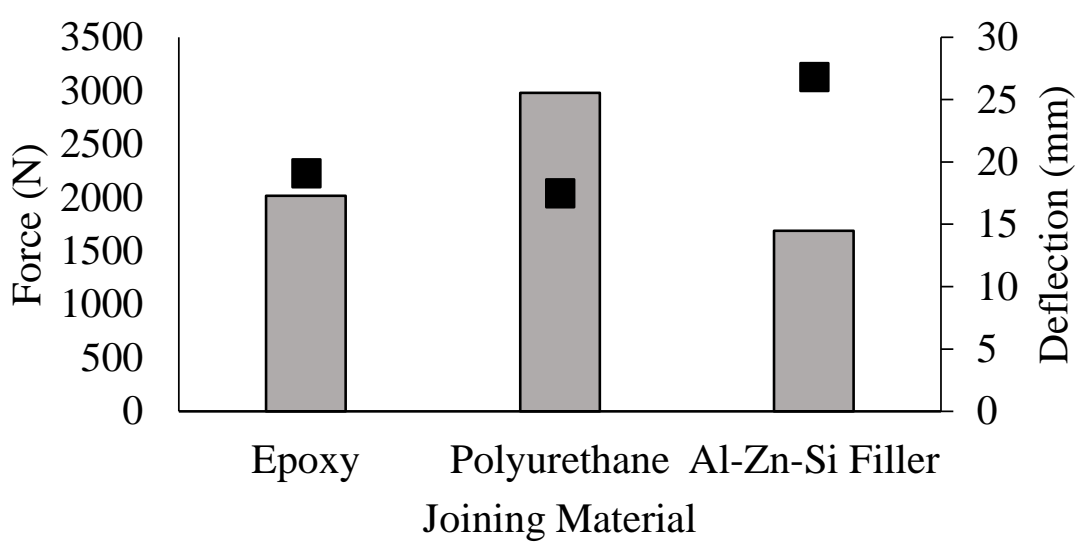

\section{$\square$ Maximum Force $\quad \square$ Deflection}

Figure 9. Force and Deflection of different joining materials subjected to drop test.

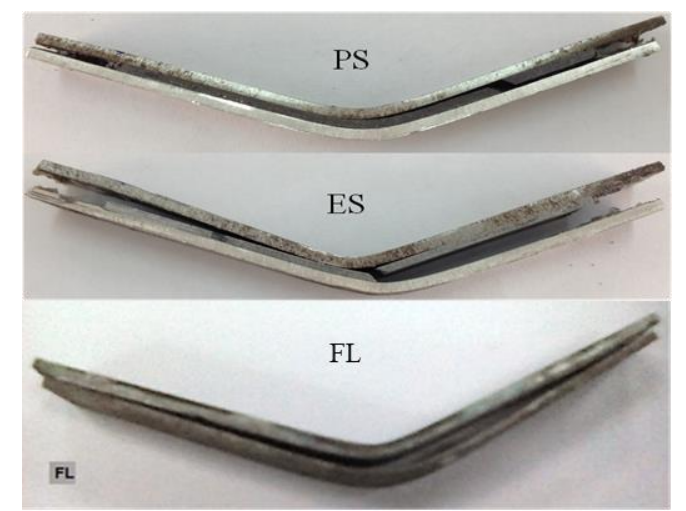

Figure 10. Fracture behaviour of polyurethane (PS), epoxy (ES) and Al-Zn-Si (FL) joined laminated panels.

The ballistic test was carried out to validate the finite element model of the laminated panel without joining materials. The images of the front face of the triple-layered plate from simulation and ballistic test are shown in Figure 11a-b. Ballistic test results showed that the projectile partially penetrated both plates with depth of penetrations varied between $1.5 \mathrm{~mm}$ to $1.9 \mathrm{~mm}$ for the triple-layered plate. The average after three shoots was calculated as $1.7 \mathrm{~mm}$. Both simulation and ballistic test showed that projectile was completely shattered. It is undeniable because the $7.62 \mathrm{~mm}$ FMJ projectile consists of soft core which would be destroyed during high velocity impact on high strength steel surface [18]. This result implied that the finite element model of triple-layered metal laminate armour plates could be used effectively to study their behaviour subject to higher level of threats with inclusive joining materials.

Ballistic test for higher threat level was performed using finite element analysis to investigate the effect of these three materials joining the Ar500 and A17075-T6 for triple-layered laminated panel configuration under high velocity impact. The final state of laminated panel with joining materials was compared to laminated panel without joining material in Figure 12 in terms of penetration depth (DOP). The panels with joining materials exhibit better performance than that of without joining material based on the penetration of triple-layered panel. Penetration depth of panel joined by polyurethane possesses the lowest depth of $22 \mathrm{~mm}$ with higher contact duration compared to panel without joining material. Time taken for the laminated panel without joining material, with Al-Zn-Si filler bond, with epoxy bond and with polyurethane bond is $67 \mu \mathrm{s}, 72 \mu \mathrm{s}, 70 \mu \mathrm{s}$ and $74 \mu \mathrm{s}$, respectively. It is believed that the ability joining materials to absorb the kinetic energy from the projectile increased has helped slowing down the projectile during penetration process [19]. This phenomenon has increased the contact duration of projectile during ballistic impact. 


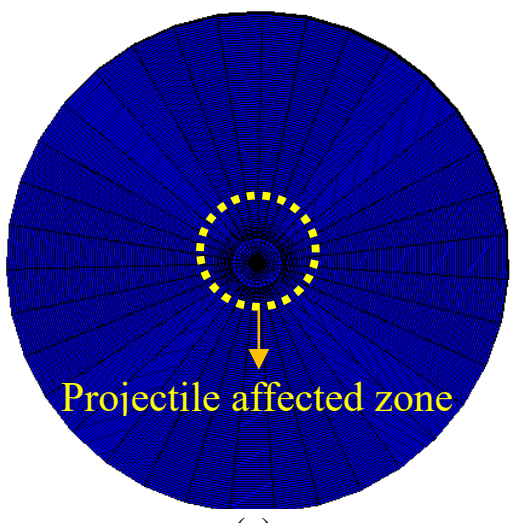

(a)

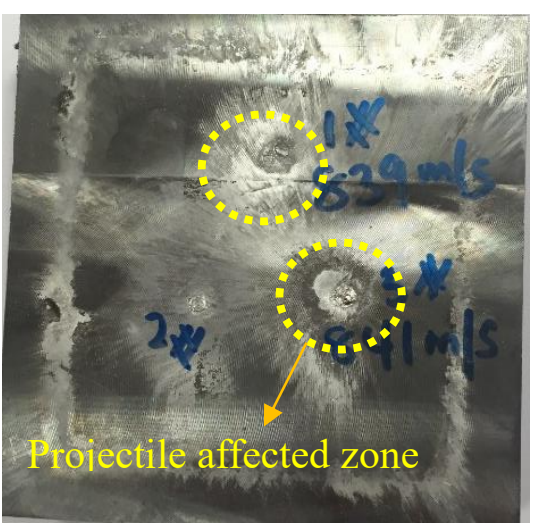

(b)

Figure 11. Comparison of triple-layered plate after the test from (a) simulation result; ballistic test.

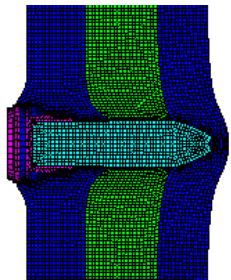

$\mathrm{DOP}=23 \mathrm{~mm}$

(a)

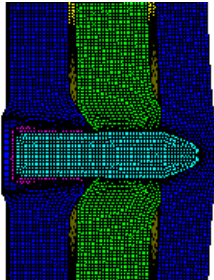

$\mathrm{DOP}=22.5 \mathrm{~mm}$

(b)

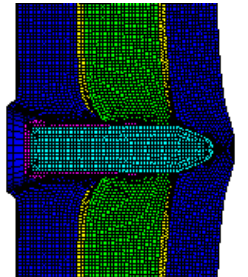

$\mathrm{DOP}=22.5 \mathrm{~mm}$

(c)

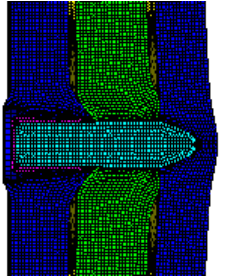

$\mathrm{DOP}=22 \mathrm{~mm}$

(d)

Figure 12. Penetration of 7.62-mm APM2 projectile at $\mathrm{t}=0.07 \mathrm{~ms}$ of initial velocity of $950 \mathrm{~m} / \mathrm{s}$ for laminated panel from simulation result: (a) without joining material, (b) with Al-Zn-Si filler bond, (c) with epoxy bond, (d) with polyurethane bond.

\section{CONCLUSION}

This paper facilitates the selection of appropriate joining material and process for laminated panels of Ar500 and Al7075-T6 to withstand ballistic impact from projectile threat. Triple-layer configuration panel was joined using two methods: brazing and adhesion techniques. Although epoxy-bonded laminate panel and Al-Zn-Si filler bonded laminate panel seem promising to withstand the low strain rate impact through bending test, but the performance decreases as the strain rate was increased through drop test. From the ballistic test conducted through finite element analysis, polyurethane bonded laminated panel performed the best under ballistic impact if only penetration depth and contact duration during penetration are taken into consideration. Polyurethane bonded laminated panel surpasses the ballistic performance of laminated panel without adhesive by $4.3 \%$ and has $10.4 \%$ longer time taken for the laminated panel to stop the projectile. Thus, polyurethane seems to be the most suitable in joining the dissimilar metal of Ar500 and Al7075-T6 as a laminated panel for armoured vehicle application.

\section{ACKNOWLEDGEMENT}

The authors wish to express their gratitude to Ministry of Higher Education Malaysia via Universiti Kebangsaan Malaysia under research funding LRGS/2013/UPNM-UKM/DS/04 for supporting this work.

\section{REFERENCES}

[1] Übeyli M, Yildirim RO, Ögel B. On the comparison of the ballistic performance of steel and laminated composite armors. Materials \& Design. 2007; 28(4):1257-1262.

[2] Übeyli M, Deniz H, Demir T, Ögel B, Gürel B, Keleş Ö. Ballistic impact performance of an armor material consisting of alumina and dual phase steel layers. Materials \& Design. 2011; 32(3):1565-1570.

[3] Børvik T, Forrestal MJ, Hopperstad OS, Warren TL, Langseth M. Perforation of AA5083-H116 aluminium plates with conicalnose steel projectiles - Calculations. International Journal of Impact Engineering. 2009; 36(3):426-437.

[4] Manes A, Serpellini F, Pagani M, Saponara M, Giglio M. Perforation and penetration of aluminium target plates by armour piercing bullets. Int Journal of Impact Engineering. 2014; 69:39-54.

[5] Forrestal MJ, Børvik T, Warren TL. Perforation of 7075-T651 Aluminum Armor Plates with 7.62 mm APM2 Bullets. Experimental Mechanics. 2010; 50(8):1245-1251. 
[6] Hou W, Zhu F, Lu G, Fang DH. Ballistic impact experiments of metallic sandwich panels with aluminium foam core. International Journal of Impact Engineering. 2010; 37:1045-1055.

[7] Jing L, Xi C,Wang Z, Zhao L. Energy absorption and failure mechanism of metallic cylindrical sandwich shells under impact loading. Materials and Design. 2013;52:470-480.

[8] Zohrabi Chakaneh J, Javid SM, Passandideh-Fard M. Surface roughness effect on droplet impact characterization: Experimental and theoretical study. Journal of Mechanical Engineering and Sciences. 2019;13(2): 5104-5125

[9] Karachalios EF, Adams RD, da Silva LFM. Single lap joints loaded in tension with high strength steel adherends. International Journal of Adhesion and Adhesives. 2013; 43:81-95.

[10] Seshadri M, Saigal S, Jagota A, Bennison SJ. Scaling of fracture energy in tensile debonding of viscoelastic films. Journal of Applied Physics. 2007; 101(9):493-504.

[11] Narinder K, Sandeep S, Rajesh R, Pardeep G, Tripathi, BN. Experimental investigations of friction stir welded AA6063 aluminum matrix composite. Journal of Mechanical Engineering and Sciences. 2018;12(4): 4127-4140.

[12] Gent AN, Petrich RP. Adhesion of viscoelastic materials to rigid substrates. Proceeding of the Royal Society A. 1969; 310(1502):433-448.

[13] Erice B, Pérez-Martín MJ, Gálvez F. An experimental and numerical study of ductile failure under quasi-static and impact loadings of Inconel 718 nickel-base superalloy. International Journal of Impact Engineering. 2014; 69:11-24.

[14] Protection levels for occupants of logistic and light armoured vehicles. STANAG level 4569. 2004.

[15] Morinière FD, Alderliesten RC, Benedictus R. Modelling of impact damage and dynamics in fibre-metal laminates - A Review. International Journal of Impact Engineering. 2014; 67:27-38.

[15] Galliot C, Rousseau J, Verchery G. Drop weight tensile impact testing of adhesively bonded carbon/epoxy laminate joints. International Journal of Adhesion and Adhesives. 2012; 35: 68-75.

[16] Kadioglu F, Adams RD. Flexible adhesives for automotive application under impact loading. International Journal of Adhesion and Adhesives. 2015; 56: 73-78

[17] Kiliç N, Bedir S, Erdik A, Ekici B, Taşdemirci A, Güden M. Ballistic behaviour of high hardness perforated armor plates against $7.62 \mathrm{~mm}$ armour piercing projectile. Materials \& Design. 2014;63:427-438.

[18] Bürger D, Rocha De Faria A, De Almeida SFM, De Melo FCL, Donadon MV. Ballistic impact simulation of an armour-piercing projectile on hybrid ceramic/fiber reinforced composite armours. International Journal of Impact Engineering. 2012; 43:63-77. 